\title{
FRONTEIRAS TEMÁTICAS DA LINGÜÍSTICA APLICADA - O QUE ESTUDAM E ONDE INTERVÊM AS PESQUISAS EM LINGÜÍSTICA APLICADA ${ }^{1}$
}

\author{
Luanda Sito * \\ Cristina Charão Marques ** \\ Letícia Santos ***
}

\begin{abstract}
RESUMO: O caráter transdisciplinar, ou mesmo indisciplinar, da Lingüistica Aplicada (LA) confere à área duas características especiais: a primeira, o constante repensar teórico-metodológico que desafia os lingüistas aplicados; a segunda, a permanente redefinição de seu(s) foco(s) de estudos. Entre a ênfase consolidada no ensino-aprendizagem de língua e a proposta de uma LA ampliada, dando conta de problemas diversos, é possivel definir as fronteiras temáticas da área no Brasil? O presente trabalho tenta responder essa pergunta analisando teses e dissertações realizadas dentro de Programas de pósgraduação de cinco universidades brasileiras, entre 2005 e 2006. Aponta, assim, um permanente movimento de suas fronteiras.
\end{abstract}

PALAVRAS-CHAVE: Lingüistica Aplicada - Transdisciplinaridade - Produção acadêmica

ABSTRACT: Transdisciplinary, or even "non-disciplinary" nature of Applied Linguistics (AL) gives the area two special characteristics: firstly, the constant theoretical and methodological reinvention, which challenges applied linguists; secondly, the permanent redefinition of its object(s) of investigation. From the consolidated emphasis on the teaching and learning of languages to the proposal of a broader $A L$, which will be concerned with a wider variety of problems, is it possible to establish thematic boundaries of this area in Brazil? The present study aims at answering this question by analyzing thesis and dissertations produced in the post-graduation courses of five Brazilian universities, between 2005 and 2006. It indicates, therefore, the field of AL reveals a permanent movement of its boundaries.

KEY WORDS: Applied Linguistics - Transdisciplinary - Academic production

\section{INTRODUÇÃO}

Neste artigo, buscamos mapear os trabalhos produzidos na área de Lingüística Aplicada (doravante LA) com o objetivo de responder a seguinte pergunta: é possível definir as fronteiras temáticas da área da LA no Brasil? Essa pergunta emergiu de um contexto de discussão sobre o caráter transdisciplinar, ou mesmo indisciplinar, da LA que confere à área duas características especiais: a primeira, um constante repensar

\footnotetext{
1 Este texto foi apresentado como trabalho de conclusão da disciplina de Lingüística Aplicada, ministrada pela Prof $f^{a}$. Dra. Margarete Schlatter, em 2007/1, do Programa de Pós-Graduação em Letras - Lingüística Aplicada da Universidade Federal do Rio Grande do Sul (PPGLET-UFRGS).

*Mestranda do Programa de Pós-Graduação em Lingüística Aplicada pela Universidade Estadual de Campinas (IEL-UNICAMP), luandasito@gmail.com.

**Mestranda do Programa de Pós-Graduação em Letras - Lingüística Aplicada pela Universidade Federal do Rio Grande do Sul (PPGLET-UFRGS), crischarao@gmail.com.

***Mestranda do Programa de Pós-Graduação em Letras - Lingüística Aplicada pela Universidade Federal do Rio Grande do Sul (PPGLET-UFRGS), ticia_santos@yahoo.com.br.
} 
teórico-metodológico que desafia os lingüistas aplicados; a segunda, uma permanente redefinição de seu(s) foco(s) de estudos. Reconhecida por sua ênfase consolidada na pesquisa de ensino-aprendizagem de língua, atualmente sua proposta se amplia para outros contextos de pesquisas, como mercado de trabalho, saúde e formação de professores. Para este trabalho, analisamos teses e dissertações realizadas dentro de programas de pós-graduação de cinco universidades brasileiras, entre 2005 e 2006 . Na primeira parte do artigo, focalizamos as discussões sobre a definição do campo de pesquisa da LA, visitando pesquisadores relevantes no campo da LA no cenário brasileiro. Na segunda parte, apresentamos a análise das produções de pesquisa na área, a partir de teses e dissertações desenvolvidas em relevantes programas de pósgraduação no país.

\section{O CAMPO DE DISCUSSÃO DA LA}

A discussão sobre a identidade da LA é bastante antiga na área e acompanha uma dinâmica reflexão sobre os pressupostos teóricos, metodológicos e os objetivos do campo. Afinal, como definimos o campo da LA? Pergunta difícil, ainda mais se levarmos em conta que seu caráter transdisciplinar (SIGNORINI; CAVALCANTI, 1998) complexifica o perfil da área. Nesse sentido, muitos se perguntam se a LA é uma disciplina, e uma disciplina de aplicação da Lingüística. Emanuel Schegloff, questionado sobre o que é a LA, faz a seguinte ponderação:

What then is applied linguistics? Perhaps is study of what applied linguists do, and how they do it. Applied linguistics might then, in a peculiar twist with a double sense, be better termed the study of applied linguistics. $\left(\right.$ SCHEGLOFF, 1990, p. 150) ${ }^{2}$

A resposta do autor nos leva a pensar quem é o lingüista aplicado, que em sua visão poderia ser todo falante. Sua resposta revela uma característica que marca a pesquisa em Lingüística Aplicada: um contínuo repensar sobre seus limites e limitações. $\mathrm{Se}$, por um lado, a pergunta que acompanha a área há quase duas décadas pode denotar certa dificuldade de se encontrar uma clara identidade teórico-metodológica entre aqueles que trabalham sob o seu amplo guarda-chuva; por outro, a presença permanente desta questão sobre o que fazem os lingüistas aplicados tem aberto possibilidades não apenas disciplinares, mas especialmente temáticas. Em outras palavras, abrem possibilidades em outros espaços sociais onde a LA pode intervir.

A questão da identidade disciplinar fluida da LA tem sido colocada no prisma dos conceitos de multidisciplinar, pluridisciplinar e transdisciplinar, que marcam boa parte da literatura auto-referente da área, como podemos ver nas obras de Celani (1998), Signorini e Cavalcanti (1998), Freire, Abrahão e Barcelos (2005), Moita Lopes (1998, 2006b) e nos Anais do VII CBLA ${ }^{3}$ (2004). Essas análises, para Alastair Pennycook (1998, p. 25), estariam revelando uma crise epistemológica, pois os paradigmas da LA não oferecem teorias para explorar o caráter político da educação de línguas e,

\footnotetext{
2 Tradução nossa: "O que é, então, a lingüística aplicada? Talvez seja o estudo sobre o que fazem os lingüistas aplicados, e como eles fazem. Lingüística Aplicada pode então, em uma peculiar brincadeira com duplo sentido, ser melhor definida como o estudo da lingüística aplicada".

${ }^{3}$ CBLA - Congresso Brasileiro de Lingüística Aplicada, ocorrido em 2004.
} 
acrescentamos, da linguagem. Muitas pesquisas da área ainda seguem os paradigmas positivista e estruturalista, nos quais a linguagem é a-política e a-histórica.

Ao discutir o conceito de LA como subárea da Lingüística, Moita Lopes (1998) comenta que as práticas de pesquisa interdisciplinar, por não constituírem disciplinas, constituem, na verdade, Indisciplina, e suscitam, por decorrência, problemas institucionais. Segundo o autor, o Indisciplinar, no entanto, envolve interesse e respeito pela voz do outro, bem como a integração de idéias de campos diferentes como uma forma de construir um pensamento crítico.

Cerca de seis anos depois, o autor retoma a discussão da INdisciplina no campo aplicado e levanta dois pontos que se referem ao trabalho transdiciplinar: a) a posição de outridade em que a LA é freqüentemente colocada, sendo que para aqueles que fazem pesquisa em LA a alteridade seria característica daqueles que trabalham justamente dentro dos limites da disciplina e não fora deles; e b) a possibilidade política no campo da LA, o que traz implicações para as trajetórias de vidas que constituem as pesquisas. Sobre o item b, Moita Lopes ressalta que

esse percurso parece essencial, uma vez que tais vozes podem não só apresentar alternativas para entender o mundo contemporâneo como também colaborar na construção de uma agenda anti-hegemônica em um mundo globalizado. (MOITA LOPES, 2006a, p. 27)

Segundo Fabrício (2006), a discussão sobre a identidade da LA que se desenvolveu ao longo dos últimos anos, principalmente a partir do final dos anos 90, refletiu as viradas conceituais ocorridas nas bases da área da LA, as quais a fizeram se debruçar sobre as práticas lingüísticas através de um olhar transdisciplinar com interesse em estabelecer vínculos com as epistemologias e os questionamentos suscitados pela vida social contemporânea. De acordo com a autora,

\footnotetext{
é por tal razão que a LA se encontra em momento de revisão de suas bases epistemológicas, a reboque da compreensão: 1) de que, se a linguagem é uma prática social, ao estudarmos a linguagem estamos estudando a sociedade e a cultura das quais ela é parte constituinte e constitutiva; 2) de que nossas práticas discursivas não são neutras, e envolvem escolhas (intencionais ou não) ideológicas e políticas, atravessadas por relações de poder, que provocam diferentes efeitos no mundo social; 3) de que há na contemporaneidade uma multiplicidade de sistemas semióticos em jogo no processo de construção de sentidos. Tais fenômenos são freqüentemente aludidos pelos termos "virada lingüística e cultural", "virada crítica", e "virada icônica". (FABRÍCIO, 2006, p. 48-49)
}

Essas viradas conceituais resultaram numa aproximação entre os estudos da linguagem e os estudos das ciências sociais, em um movimento que interseccionou os questionamentos e as metodologias, bem como as bases teóricas das disciplinas envolvidas, que passaram, assim, a compartilhar objetivos, reflexões e compreensões do mundo contemporâneo.

Tendo em vista esse processo de mudanças e diálogos transdisciplinares, buscamos ver como esse movimento se reflete no campo de estudos da LA no Brasil. Este trabalho pretende, então, apontar se e como os limites epistemológicos da Lingüística Aplicada vêm sendo redefinidos pela produção acadêmica. Utilizamos como material de análise as teses e as dissertações produzidas em cinco Programas de pósgraduação reconhecidos no campo da LA (ou Estudos da Linguagem, com linha de pesquisa específica para a LA) de universidades brasileiras, durante os anos de 2005 e 2006. Dentre as universidades, temos: a Universidade Federal do Rio Grande do Sul 
(UFRGS) - PPG Letras Estudos da Linguagem/Lingüística Aplicada; Pontifícia Universidade Católica de São Paulo (PUC-SP) - PPG Lingüística Aplicada; Universidade Estadual de Campinas - PPG-IEL Lingüística Aplicada; Pontifícia Universidade Católica do Rio Grande do Sul (PUC-RS) - PPG LETRAS Lingüística Aplicada e Universidade do Vale do Rio dos Sinos (UNISINOS) - PPG Lingüística Aplicada.

\section{História e consolidações}

A história da LA é bem recente no Brasil. Segundo Cavalcanti (2004), num artigo no qual discute a história da área, em 1971 foi fundado o primeiro programa de pós-graduação na PUC-SP, por Maria Alba Celani, reconhecida hoje como a "mãe" da Lingüística Aplicada no país. Nesse período, o conceito da LA estava profundamente vinculado a uma aplicação da lingüística teórica e a questões de sala de aula, principalmente no ensino de línguas estrangeiras.

Nos anos 80, houve um florescimento da LA, com a criação de mais um programa de pós-graduação específico (na Unicamp, em 1986) e a criação de um grupo de trabalho na Associação Nacional de Pós-Graduação e Pesquisa em Letras e Lingüística (ANPOLL). Neste período, também iniciou a publicação de revistas específicas na área, ocorrendo dentre outros encontros, o primeiro Congresso Brasileiro de Lingüística Aplicada, em 1986.

A consolidação da área se dá, de fato, na década de 90. Em junho desse ano, foi fundada a Associação de Lingüística Aplicada do Brasil (ALAB) durante a V Reunião Anual da Associação Nacional de Programas de Pós-graduação em Letras e Lingüística. A entidade (ALAB) congrega hoje aproximadamente mil associados em torno da pesquisa aplicada na esfera da linguagem. A ALAB promove congressos nacionais - 0 último realizado no mês de julho de 2007, em Brasília - e distribui gratuitamente a seus sócios a publicação Revista Brasileira de Lingüística Aplicada, um periódico bianual com publicação sob a responsabilidade do Programa de Pós-Graduação em Estudos Lingüísticos da UFMG. É representada na Association International de Linguistique Appliquée (AILA) através de dois vice-presidentes eleitos. Nessa década, começa a haver um crescimento das subáreas em LA, como língua e gênero, língua e novas tecnologias, discurso e identidade.

Moita Lopes afirma que "a área de ensino/aprendizagem de línguas é sem dúvida a mais avançada em Lingüística Aplicada" (1996, p. 11). E isso se daria, provavelmente, devido à importância da linguagem na educação formal. Segundo o autor, a maior parte da pesquisa que se faz em LA no Brasil e no mundo enfoca questões relativas ao uso da linguagem em sala de aula, englobando, portanto, aspectos de ensino/aprendizagem de línguas. Ao apresentar a área a partir desse recorte, com o objetivo de dialogar com professores de línguas e estudantes de Letras, aborda cinco tópicos da área de LA: "o aprendiz e o professor de línguas, a sala de aula de línguas como contexto de aprendizagem, a língua do aprendiz, uma abordagem de ensino de língua estrangeira, a formação do professor". Todos esses são temas que já possuíam seus espaços dentro dos estudos da área. No entanto, na construção desse livro com enfoque somente na sala de aula/aula de língua, Moita Lopes não abordou outros temas que estavam se consolidando na LA, como, por exemplo, os conflitos institucionais, que já eram presentes nessa época conforme apresentação feita por Inês Signorini nos trabalhos do IV CBLA (1998). Nesse livro, o autor levanta questões metodológicas também como definidoras da área e conceitua a pesquisa em LA em cinco pontos: i) 
natureza aplicada em Ciências Sociais, ii) foco na linguagem do ponto de vista processual, iii) natureza interdisciplinar e mediadora, iv) formulação teórica, e v) uso de métodos de investigação de base interpretativista, se contrapondo a uma postura metodológica de base positivista, a qual também é criticada por Pennycook (1998) e, mais enfaticamente, por Moita Lopes (2006b).

Dois anos depois, Signorini (1998) faz uma análise quantitativa dos trabalhos apresentados no evento IV Congresso Brasileiro de Lingüística Aplicada, ocorrido em 1995 - conferências, mesas-redondas e comunicações. Dos três Congressos anteriores, cita subáreas que estavam se consolidando nas pesquisas em LA. Dentre elas, havia Ensino/aprendizagem de língua materna (LM), com 30,1\% entre os trabalhos apresentados, Ensino/aprendizagem de segunda língua (L2) e língua estrangeira (LE), com 10,5\%, e Tradução e Educação bilíngüe, com $0,9 \%$. Em sua conclusão, assinala que a LA está marcada por uma diversidade de temas, perspectivas e abordagem, por um interesse pelo componente sócio-histórico e ideológico nas práticas, e por um isolamento dos grupos de pesquisa que trabalham com o mesmo assunto. No VII Congresso da área, ocorrido em 2004, Cavalcanti retoma os desafios traçados por Moita Lopes quase dez anos atrás, e aponta para:

a ampliação do foco da atividade do pesquisador para os contextos de uso da linguagem outros que não a sala de aula, em uma tentativa de mudar "as práticas discursivas que usurpam o poder e as vozes dos trabalhadores, pacientes, minorias. ${ }^{4}$

Atualmente, o Grupo de Trabalho de LA da Associação Nacional de PósGraduação e Pesquisa em Letras e Lingüística - ANPOLL é subdivido em três sub-GTs: o Sub-GT Ensino-Aprendizagem de Línguas, o Sub-GT de Formação de professores e o sub-GT de Gêneros Discursivos. O GT-LA da ANPOLL é um dos 32 GTs da Associação que associa programas de pós-graduação em Letras e Lingüística em todo o Brasil. A atuação dos grupos de trabalho temáticos é fundamental na constituição da Associação.

\section{Novas definições da área}

Moita Lopes (2006a) conceitua a LA como mestiça ou nômade, por ser transdisciplinar, ou melhor, indisciplinar, ou seja, uma área de estudo que mescla diferentes aportes teórico-metodológicos e inspira suas questões a partir dessas diferentes fontes. Contrapõe sua proposta, de uma LA ideológica, a uma LA autônoma, pois propõe uma ruptura com o estruturalismo e o positivismo em sua produção, utilizando-se do conceito de língua como atravessada por relações de poder e intrinsecamente política. Para o autor, a LA é continuamente auto-reflexiva e:

precisa dialogar com teorias que têm levado a uma profunda reconsideração dos modos de produzir conhecimento em ciência sociais (cf. Signorini,

\footnotetext{
${ }^{4}$ Palestra proferida no VII Congresso Brasileiro de Lingüística Aplicada, de 10 a 14 de outubro de 2004, na PUC-SP, São Paulo. Texto disponível na obra "Lingüística Aplicada e Contemporaneidade", organizada por Maximina M. Freire, Maria Helena Vieira-Abrahão e Ana Maria F. Barcelos, composta por vinte e um artigos, resultantes de conferências, plenárias ou mesas redondas apresentadas no VII Congresso Brasileiro promovido pela Associação.
} 
$1998 b)^{5}$, na tentativa de compreender nossos tempos e de abrir espaço para visões alternativas ou para ouvir outras vozes que possam revigorar nossa vida social ou vê-la compreendida por outras histórias. (MOITA LOPES, 2006a, p. 23)

Resumindo nas palavras de Pennycook, "todo conhecimento é político" (PENNYCOOK, 2001 apud MOITA LOPES, 2006a, p. 21). A proposta de LA, apresentada por Moita Lopes, é a de uma área que se pretenda como intervenção teórica e política, ou seja, uma aliança perfeita entre o compromisso social e teórico. Nesse sentido, expões que:

a Lingüística Aplicada parece ter vocação para uma atitude transdisciplinar. Essa preocupação com o social, com o humano, há tempos tem sido o objeto de pesquisas em Lingüística Aplicada e, de fato, é componente fundamental na definição da disciplina. (MOITA LOPES, 2006a, p. 133)

O lingüista Rajagopalan (2006), discutindo sobre a relação entre a LA e a Lingüística, afirma que o entendimento da LA como "atividade mediadora, de caráter mais etnográfico" $" 6$ pode não ser muito produtivo para o campo de estudos. Segundo ele:

\begin{abstract}
o problema desse modo de pensar a relação entre a lingüística e a sociedade está no fato de que não passa de vinho velho (a idéia de que a LA deve se contentar com o papel secundário em relação à disciplina-mãe) em garrafa nova (apelo à etnografia que, à primeira vista, nos leva a pensar que de fato está havendo uma vontade, por parte do lingüista teórico, de negociar os sentidos com a sociedade ampla). Porém, o vinho já passou do tempo, transformou-se em vinagre. Ou seja, o que precisamos é repensar tudo de forma radical - não procurar pequenos reparos aqui ou acolá. (RAJAGOPALAN, 2006, p. 165)
\end{abstract}

Rajagopalan observa que há mudanças na postura da LA, pois o campo de estudos deixou de ser uma aplicação da Lingüística para produzir teorias a partir de outras bases e assumir uma posição crítica. Nesse sentido, afirma que "a tendência em curso pode até ter reservado destino um tanto irônico para a lingüística dita teórica", pois aponta que não ser difícil imaginar, dada a falta de intervenção prática deste campo, que a LA venha a ocupar seu lugar, inclusive ampliando seus conceitos e reflexões teóricas.

Fabrício (2006) relê a crise dos conceitos da ciência na perspectiva da LA a partir dos pressupostos de Nietzsche, Foucault e Wittgenstein, lembrando a crise epistemológica citada por Pennycook. Para ela,

um mundo em crise, que vê abalada a crença no dogma, na lógica formal abstrata e no predomínio da razão na filosofia, na ciência, na moral e na arte. Uma época de mudança geral nas perspectivas e de inovações sociais, econômicas e tecnológicas, época na qual convivem idéias paradoxais: racionalismo e irracionalismo, cientificismo e misticismo, humanismo e barbárie, intelectualismo e antiintelectualismo. Panorama responsável pela perda de referências explícitas e gerador de indivíduos em choque, em

\footnotetext{
${ }^{5}$ Reproduzindo a nota do autor: "Signorini (1998b, p. 108) chama a atenção para o modo como uma LA atual se expõe à multiplicidade de paradigmas que constituem o universo científico contemporâneo", promovendo um repensar contínuo de "seu universo de referência".

${ }^{6} \mathrm{O}$ autor faz referência a discussão feita em Widdowson (2000).
} 
conflito e desorientados, devido ao colapso de seu sistema de crenças e valores. Mundo contemporâneo? (FABRÍCIO, 2006, p. 45)

Pennycook (2006), a partir das rupturas promovidas pelos trabalhos de autores como Foucault, Fanon e Habermas, reitera a relevância das viradas conceituais, apontadas também por Fabrício (2006), e a importância de elas serem incorporadas pela LA. Para ele, é necessário ter instrumentos políticos e epistemológicos que permitam transgredir os limites do pensamento e da política tradicionais, pois todo projeto crítico precisa tanto de uma agenda política crítica como de disponibilidade para questionar os conceitos com que se lida.

Nesse sentido, a LA precisa buscar em outras áreas um novo olhar para a língua, que envolva as relações sociais ideológicas, de poder e de desigualdades. Como exemplo, trazemos o artigo de Rampton (2006), no qual discute o percurso das pesquisas na área da sociolingüística migrando em direção à microssociologia e, com isso, a revisão do conceito de falante que esse deslocamento produziu:

Em 1964, Goffman escreveu um trabalho chamado A situação negligenciada. Naquela época, muitas idéias novas estavam sendo veiculadas, tanto na descrição lingüística como na documentação de fatores sociais que a afetavam, mas pouca atenção estava sendo dada às propriedades distintivas das arenas onde a linguagem e os fatores sociais se uniam. Desde então, recebemos uma bateria muito impressionante descritivos elaborados por Goffman (rever citação) e por uma série de outras escolas e paradigmas: a etnografia da comunicação, a análise da conversação, a sociolingüística interacional, a análise crítica do discurso, etc. (RAMPTON, 2006, p. 123)

O percurso do macro para o micro abordado pelo autor promove um questionamento da importância contextual e situacional nas produções científicas de sua área. Que visões de língua estão por trás de nossas produções? O que outras áreas têm a dizer sobre a língua/linguagem? Essas são questões envolvidas no processo de transdisciplinaridade. Em síntese, para a LA dar conta de seu caráter transdisciplinar, precisa ser, nas palavras de Moita Lopes, transdisciplinar, ao fazer dialogar conceitos de áreas diversas e distantes, romper com o paradigma de ciência no qual fomos formados.

Nesta discussão sobre o que é a LA, temos diferentes visões sobre a área. As críticas se somam de correntes muito distintas. E, afinal, acabam por ser distintas também as avaliações sobre a permeabilidade de fato da área às reflexões que acumula sobre o seu fazer teórico e metodológico.

Para o lingüista aplicado Kumaravadivelu (2006), por exemplo, é preciso certo grau de ceticismo em relação ao percurso da área: apesar de toda a ênfase nos problemas do mundo real e dos problemas
cotidianos relacionados com a linguagem, a LA como campo é ainda
informada quase que exclusivamente por questões de base lingüística
referentes à política e ao planejamento da língua inglesa ao ensino e a
aprendizagem de inglês como segunda ou língua estrangeira.
(KUMARAVADIVELU, 2006, p. 136-137)

Por outro lado, críticos, como Moita Lopes, apresentam o campo da LA como uma busca constante de novos horizontes. Para ele, a LA está traçando caminhos e identidades para a nova ciência: 
A pesquisa em LA tem se espraiado para uma série de contextos diferentes da sala de aula de LE: da sala de aula de LM para as empresas, para as clinicas de saúde, para delegacias de mulheres, etc., ainda que predominem aspectos referentes a educação lingüística. (MOITA LOPES, 2006a, p. 19)

Busquemos olhar, agora, como esse delineamento da área da LA se apresenta nos trabalhos de pesquisa que se inserem no campo.

\section{BUSCANDO AS NOVAS FRONTEIRAS}

Considerando a mestiçagem disciplinar da LA para qual aponta Moita Lopes, como então dar contornos mais nítidos ao movimento que, embora possa ter intensidade diferente para os dois autores, não pode ser negado? Como estabelecer as novas fronteiras da LA? Parece interessante pensar que o que pode ajudar nesta tarefa é voltar os olhos para a área, tendo em mente esta vocação "militante", este caráter intervencionista da LA contemporânea.

Pensando nisso, nos propusemos a olhar a produção acadêmica elaborada no Brasil sob o título institucional de Lingüística Aplicada, buscando identificar se esta produção estabelece algum tipo de fronteira para área.

Objetivando recortar melhor nosso objeto de análise, optamos por pesquisar dissertações de mestrado e teses de doutorado realizadas em instituições de ensino superior que mantêm linhas de pesquisa em Lingüística Aplicada em seus Programas de pós-graduação. As análises foram feitas sobre os resumos dos trabalhos, disponíveis na internet através das páginas dos programas ou nas bibliotecas de ditas instituições. Foram identificados 204 trabalhos, entre teses e dissertações defendidas nos anos de 2005 e 2006.

Os trabalhos foram, então, analisados em função de sua relação com as temáticas que vamos chamar aqui "consolidadas", com base no balanço dos trabalhos do IV CBLA apresentado por Signorini (1998) e Moita Lopes (1996): ensino/aprendizagem de língua estrangeira, ensino/aprendizagem de língua materna, bilingüismo e tradução. Após esta primeira triagem, os resumos (abstracts) dos trabalhos considerados como filiados a temáticas em consolidação dentro da LA foram analisados mais profundamente, buscando identificar áreas de intervenção comuns, que pudessem apontar afinal para quais "problemas no mundo" os lingüistas aplicados estariam olhando.

Já durante a primeira classificação, percebemos que, dada a feição institucional de alguns programas, nos quais a Lingüística Aplicada é a única área dos Estudos da Língua e/ou da Linguagem alternativa à Literatura, parte dos trabalhos estava claramente voltada para questões de áreas da Lingüística (tais como morfologia, fonética, teoria lingüística). Desta forma, para além da classificação "Tema consolidado" e "Tema em consolidação", foi preciso apontar ainda uma outra categoria, a "Lingüística Geral", para aqueles trabalhos que tinham enfoque na língua sem olhar para o contexto social.

Os resultados da Tabela 1 apontam a manutenção de uma tendência de vinculação da pesquisa em LA com o contexto e a discussão de ensino/aprendizagem de línguas, bilingüismo e tradução. Não se pode negar, no entanto, o avanço dos trabalhos que gravitam fora deste núcleo consolidado da área. 
Tabela 1 - Temas da LA

\begin{tabular}{lcc}
\hline & Total & $\%$ \\
\hline Tema consolidado & 123 & 60 \\
\hline Tema em consolidação & 65 & 32 \\
\hline Lingüistica geral & 16 & 8 \\
\hline Total & 204 & 100 \\
\hline
\end{tabular}

Como podemos ver, na categoria Tema consolidado constam $60 \%$ dos trabalhos; os $40 \%$ restantes distribuem-se em $32 \%$ em trabalhos em Tema em consolidação e $8 \%$ em Lingüistica Geral.

A partir destes dados, trabalhou-se para tentar identificar o foco destes trabalhos que representaram um terço daqueles realizados dentro dos programas de pós-graduação e que representariam temáticas em consolidação na área. Entende-se que uma análise mais pormenorizada destes trabalhos poderia dar uma noção mais refinada dos movimentos recentes da pesquisa em LA.

Analisando os resumos (abstracts) das obras, buscamos responder as perguntas que seguem: qual o tema elou objetivo do trabalho, qual o aporte teórico lingüistico utilizado, o trabalho lança mão de aportes teóricos de outras áreas e, por fim, qual era o local de intervenção deste trabalho no mundo. Com essas questões respondidas, tentamos agrupar esses diversos temas em "áreas de intervenção".

Foram seis as áreas de intervenção identificadas: 1) Caracterização de gêneros do discurso (gêneros jornalísticos, pesquisa científica, literatura, textos jurídicos, contratos); 2) Língua e contexto escolar (identidade dos profissionais de educação, educação inclusiva, convivência surdos/ouvintes em ambiente escolar, atividades e instâncias de gestão escolar, relações de poder); 3) Língua e contexto social (identidade de minorias, especificidades lingüísticas de grupos sociais, aquisição interpelada por noções sociológicas); 4) Língua e mundo digital (programação, ensino a distância, gêneros digitais); 5) Língua e mundo do trabalho (conflitos profissionais, humanização do atendimento de profissionais da saúde, publicidade, telemarketing, hotelaria) e 6) Patologias da linguagem. Poderemos ver melhor essa distribuição na Tabela 2. 
Tabela 2 - Áreas de intervenção da LA

\begin{tabular}{lcc}
\hline & TOTAL & $\%$ \\
\hline Língua e contexto escolar & 18 & 28 \\
\hline Língua e mundo do trabalho & 13 & 20 \\
\hline $\begin{array}{l}\text { Caracterização de gêneros do } \\
\text { discurso }\end{array}$ & 11 & 17 \\
\hline Língua e contexto social & 11 & 17 \\
\hline Língua e mundo digital & 9 & 13 \\
\hline Patologias da linguagem & 3 & 5 \\
\hline TOTAL & $\mathbf{6 5}$ & $\mathbf{1 0 0}$ \\
\hline
\end{tabular}

É possível perceber, observando a Tabela acima, que o movimento mais sensível nas fronteiras da LA foi a ampliação da questão da língua na escola. Foram 18 trabalhos identificados como focados na área Língua e contexto escolar. Como sugere o próprio nome dado à categoria, a escola passa a ser vista como local complexo de interação social. A proximidade entre a situação específica de ensino/aprendizagem e as demais situações geradoras de potenciais conflitos mediados pela linguagem no mundo escolar parece colocar, para o lingüista aplicado, uma série de outras perguntas, que vão do pedagógico (para além da sala de aula de português ou língua estrangeira) ao organizacional, passando por temas transversais, como a educação inclusiva. O contexto da sala de aula se mantém como campo de grande interesse, portanto, mas nesta nova temática os conhecimentos lingüísticos são mobilizados para dar conta das relações sociais que se dão no espaço escolar.

Outro resultado que sugere a mesma lógica da "contaminação por proximidade" é a presença de um bom número de trabalhos voltados para a identificação de gêneros do discurso. Uma vez que tal temática foi colocada em definitivo no campo do ensino de línguas pelos Parâmetros Curriculares Nacionais, é possível supor que o interesse crescente dos pesquisadores pela definição teórica a respeito dos gêneros tenha levantando também novas questões sobre determinadas práticas textuais. É preciso ressaltar que nenhum dos trabalhos sobre gênero focou gêneros da oralidade.

As diferentes práticas profissionais que têm no uso da língua um aspecto definidor entram no foco das pesquisas em LA com força considerável, tendo sido identificados 13 trabalhos como pertencentes à área de intervenção Língua e mundo do trabalho. É interessante notar como são diversos estes trabalhos em relação àqueles também incluídos nesta categoria e que tratam das profissões relacionadas à educação, $o$ professor em especial. Nesses últimos, tenta-se colocar as metodologias criadas a partir das diferentes áreas da teoria lingüística (da análise do discurso à gramática sistêmicofuncional) a serviço da tarefa de esboçar traços identitários da profissão do educador. Já os trabalhos que olham para os demais campos profissionais parecem ter como foco a resolução de problemas específicos das relações sociais permeadas pela linguagem que ocorrem dentro desses contextos. Assim, temos trabalhos como a relação entre pais e fonoaudiólogos ou conflitos entre chefes e funcionários em uma empresa. 


\section{CONSIDERAÇÕES FINAIS}

O movimento das fronteiras da LA pareceu ser marcado por um aumento no número de trabalhos tratando de temas ainda não consolidados dentro da área, voltados principalmente para o uso da linguagem em contextos em que a reflexão sobre ela pode contribuir para a compreensão e solução dos conflitos existentes. Nesse sentido, demonstram buscar uma intervenção no campo de estudos. Por outro lado, também foi possível perceber, conforme visto na Tabela 1, que os trabalhos de Lingüistica Geral com foco na língua continuaram com espaço na área da LA. Ressaltamos, no entanto, que este resultado parece ser menos uma incompreensão da área e mais uma contingência da estrutura dos programas de pós-graduação.

Os trabalhos sobre as relações entre língua e mundo digital não proliferaram muito, ainda que tal tema já estivesse apontado há mais de 15 anos como algo desafiador para a pesquisa. Da mesma forma, chama a atenção o fato de as pesquisas preocupadas com a variação lingüística e o uso da língua por diferentes grupos sociais, aqui classificados na categoria Língua e contexto social, aparecerem em número pouco expressivo, considerando a existência de projetos nacionais que dão conta destas questões. Por fim, as patologias da linguagem mereceram a atenção de apenas três trabalhos: dois deles claramente desenvolvidos na perspectiva da aproximação entre a fonoaudiologia e as teorias lingüísticas, e o terceiro buscando conectar genética e disfunções lingüísticas.

A Tabela 2 permite apontar movimentos claros nas fronteiras temáticas da LA na direção da "militância da LA", conforme discussões em Moita Lopes (2006b). Isso não define, porém, que esses Temas em consolidação, já mencionados há quase 15 anos, estejam de fato redefinindo as fronteiras da LA. O campo Tema consolidado concentrou mais da metade dos trabalhos produzidos e isso deve ser observado.

Os trabalhos categorizados como Tema em consolidação parecem apontar para alargamentos nos estudos de LA em direção a uma Lingüística Aplicada comprometida com os conflitos via uso da linguagem. Nesse perfil de LA, os trabalhos não consideraram apenas a sua variante central - a língua - de uma nova perspectiva, mas também demonstraram um objetivo politizado (no sentido de ser compreendida também como um objeto social atravessado por relações de poder) e o compromisso dos pesquisadores com a tarefa de ser interveniente, de propor soluções ou, no mínimo, denunciar problemas.

\section{REFERÊNCIAS}

CAVALCANTI, Marilda. Applied Linguistics: Brazilian perspectives. AILA Review, v.17, p. 23-30, 2004.

CELANI, Maria Alba A. Transdisciplinaridade na Lingüística Aplicada no Brasil. In: SIGNORINI, Inês; CAVALCANTI, Marilda (orgs.). Lingüística Aplicada e transdisciplinaridade. São Paulo: Mercado de Letras, 1998, p. 129-142.

FABRÍCIO, Branca Falabella. Lingüística aplicada como espaço de “desaprendizagem”. Redescrições em curso. In: MOITA LOPES, Luiz Paulo (org.). Por uma lingüistica aplicada INdisciplinar. São Paulo: Parábola, 2006, p. 45-65.

FREIRE, Maximina; ABRAHẪ, Maria Helena Vieira; BARCELOS, Ana Maria Ferreira (orgs.). Lingüística Aplicada e Contemporaneidade. Campinas, SP: ALAB, Pontes Editores, 2005. 
KUMARAVADIVELU, B. A lingüística aplicada na era da globalização. In: MOITA LOPES, Luiz Paulo (org.). Por uma lingüística aplicada INdisciplinar. São Paulo: Parábola, 2006, p. 129-148.

MOITA LOPES, Luiz Paulo. Oficina de lingüística Aplicada. SP: Mercado de Letras, 1996.

. A transdisciplinaridade é possível em Lingüística Aplicada? In: SIGNORINI, Inês; CAVALCANTI, Marilda (orgs.). Lingüística Aplicada e transdisciplinaridade. São Paulo: Mercado de Letras, 1998, p. 113-128.

. Uma lingüística aplicada mestiça e ideológica: interrogando o campo como lingüista aplicado. In: Paulo: Parábola, 2006a, p. 13-43.

(org.). Por uma lingüística aplicada INdisciplinar. São Paulo: Parábola, 2006b.

PENNYCOOK, Alastair. A Lingüística Aplicada dos anos 90: em defesa de uma abordagem crítica. In: SIGNORINI, Inês; CAVALCANTI, Marilda (orgs.). Lingüística Aplicada e transdisciplinaridade. São Paulo: Mercado de Letras, 1998, p. 23-49.

Uma lingüística aplicada transgressiva. In: MOITA LOPES, Luiz Paulo (org.). Por uma lingüística aplicada INdisciplinar. São Paulo: Parábola, 2006, p. 67-83.

RAJAGOPALAN, Kanavillil. Repensar o papel da lingüística aplicada. In: MOITA LOPES, Luiz Paulo (org.). Por uma lingüística aplicada INdisciplinar. São Paulo: Parábola, 2006, p. 149-167.

RAMPTON, Ben. Continuidade e mudança nas visões de sociedade em lingüística aplicada. In: MOITA LOPES, Luiz Paulo (org.). Por uma lingüística aplicada INdisciplinar. São Paulo: Parábola, 2006, p. 109-128.

SCHEGLOFF, Emanuel. Who is an applied linguist? University of California: special feature roudtable. Definin our field: unity in diversity. Issues in Applied Linguistics, v.1, n. 2, p. 149-166, 1990.

SIGNORINI, Inês. CBLA 1995: uma amostragem da pesquisa no Brasil. In: SIGNORINI, Inês; CAVALCANTI, Marilda (orgs.). Lingüistica Aplicada $e$ transdisciplinaridade. São Paulo: Mercado de Letras, 1998, p. 171-184.

SIGNORINI, Inês; CAVALCANTI, Marilda (orgs.). Lingüística Aplicada e transdisciplinaridade. São Paulo: Mercado de Letras, 1998. 